\title{
ASSESSMENT OF DISINFECTION AND CLEANING VALIDATION IN CENTRAL LABORATORY, MBS HOSPITAL, KOTA
}

\author{
Seema Malav ${ }^{1}$, Naveen Saxena ${ }^{2}$
}

${ }^{1}$ Senior Demonstrator, Department of Microbiology, Government Medical College, Kota.

2Professor, Department of Microbiology, Government Medical College, Kota.

\section{BACKGROUND}

ABSTRACT

Many outbreaks are still caused by contaminated surfaces, and the technical drawbacks of liquid disinfectants may be partially to blame for the high facility-acquired infection rates in health care. These outbreaks have been reported when auxiliary hospital staff members have not followed appropriate protocols and have lacked supervision by Infection Control Committee.

\section{MATERIALS AND METHODS}

A total of 36 samples were collected by sterile swab sticks. From each site, three sets of samples were collected by the sterile swab sticks, the first sample being after the day's work was completed, the second after cleaning had been done the next day and the third after cleaning was correctly completed under supervision. All samples were collected from different sites (Laboratory slab, floor, test tubes and serology discarding jars). The swabs were dipped in thioglycolate broth after collection, from where it was later plated on standard plates by lawn culture after standardisation on McFarland $0.5 \% \mathrm{BaSO}_{4}$. Colonies of growth were counted by colony counter. All results were calculated in logarithm.

\section{RESULTS}

After disinfecting with non-calibrated disinfectant without specified contact time, there was unsatisfactory log reduction found for various microorganisms. When all disinfectants were used in calibrated and prescribed manner with all SOPs having been followed, there were satisfactory results. A careful assessment of its physical area is needed with a view to improvement and the installation of adequate resources to carry out techniques in material traceability and professional and environmental safety. Protocols, procedures and written routines need to be validated in terms of applicability and to be readily available in each area depending on its specific characteristics.

\section{CONCLUSION}

Most disinfectant program failures occur either because the wrong chemistry disinfectant was selected or because the right chemistry is not applied properly as per SOP. A careful assessment of its physical area is needed with a view of improvement and the installation of adequate resources to carry out techniques in material traceability and professional and environmental safety.

\section{KEYWORDS}

Disinfection, Auxiliary Staff, Validation.

HOW TO CITE THIS ARTICLE: Malav S, Saxena N. Assessment of disinfection and cleaning validation in central laboratory, MBS hospital, Kota. J. Evolution Med. Dent. Sci. 2018;7(10):1259-1262, DOI: 10.14260/jemds/2018/287

\section{BACKGROUND}

Traditional disinfectants have undoubtedly prevented a great number of infections over the years. Disinfectants used in hospitals and laboratories must be tested periodically to ascertain its potency and efficacy. As certain disinfectants lose potency on standing and addition of organic matter, their efficacy must be tested. ${ }^{1}$

Appropriate disinfection and sterilisation procedures are a must for control of hospital-acquired infection, as failure can result in many hospital-acquired infections, thus leading to increased cost, morbidity and mortality. Disinfection in hospital practice is mainly achieved either by surface disinfection (e.g. disinfection of surfaces of the tables,

'Financial or Other Competing Interest': None.

Submission 02-11-2017, Peer Review 15-02-2018,

Acceptance 22-02-2018, Published 05-03-2018.

Corresponding Author:

Dr. Naveen Saxena,

Central Laboratory,

MBS Hospital, Kota.

E-mail: drnaveen_saxena@yahoo.com

DOI: $10.14260 /$ jemds $/ 2018 / 287$ trolleys, instruments, walls and floors, etc.) or immersing contaminated objects in disinfectant solution. Disinfectants may also be used to chemically treat infectious hospital waste, especially the disposable plastic and microbiological wastes. Regrettably, many disease outbreaks are still spread by contaminated surfaces and the technical drawbacks of liquid disinfectants may be partially to blame for high facilityacquired infection rates in health care.

A working definition for disinfection process validation is "Establishing documented evidence that a disinfection process will consistently remove or inactivate known or possible pathogens from inanimate objects." The main reasons of disinfection failure in practice are-

- $\quad$ Product not applied liberally for the stipulated period of time.

- Wrong active ingredient in use for the microorganisms of concern.

- Contaminated surfaces and hotspots are missed by cleaning staff.

- In routine practice of disinfection, the ratio of disinfectant volume used to floor surface area is erroneous. 
- The volume of disinfectant required to get true disinfection from liquid chemicals on a surface is simply on approximation in many cases.

Targeted surface disinfection is a major measure of standard infection control. The surface disinfectants must be effective against the targeted pathogens. Many hospitals are still using phenolic disinfectants, while their use is being discouraged throughout advanced countries. Toxicity issues have led to discontinued use of glutaraldehyde in some developed countries.

The auxiliary hospital staff lacks proper training and sensitisation of calibrated concentration with disinfectant volume along with contact time to achieve good results.

Because these standard tests cannot be performed by the laboratories belonging to small hospitals, one has to solely rely upon the literature provided by the manufacturer regarding the efficiency of the disinfectants. Almost all the manufacturers claim their disinfectant as a broad-spectrum antimicrobial agent suitable for diverse applications.

Keeping in view the above, the following study was planned with an aim to evaluate and compare the practically achieved disinfection efficacy of some locally available disinfectants for disinfection of surfaces and infectious microbiological and other hospital wastes keeping their costeffectiveness in mind. The efficacy was tested against locally isolated highly drug-resistant isolates of Klebsiella pneumoniae, Enterobacter aerogenes, Acinetobacter baumannii, Pseudomonas aeruginosa, methicillin-resistant Staphylococcus aureus (MRSA), Candida albicans and standard strain of Salmonella typhi.

Many outbreaks have been reported when auxiliary hospital staff members have not followed appropriate protocols and also lack supervision by an Infection Control Committee. Most of the time, disinfectants are used in a noncalibrated manner. Surfaces near patients and high-touch surfaces must be effectively disinfected.

\section{Aim and Objective}

Main objective of our study was to identify effectiveness of various disinfectants in various cleaning procedures like floor cleaning, glassware cleaning and discarding jars used by the auxiliary staff.

\section{MATERIALS AND METHODS}

This study was conducted in Central Laboratory, MBS Hospital, Kota. This was a cross-sectional study (Descriptive type). All sampling was done by sterile swab sticks. Subsequently, it was dipped in thioglycolate broth with standardisation on McFarland $0.5 \% \mathrm{BaSO}_{4}$ later plated on standard plates by lawn culture. Other method of sampling was contact plate from all the sampling points.

All microorganisms grown were confirmed by the Gram's stain and various standard biochemical reactions. All disinfectant used their storage and expiry was monitored before the experiment.

A total of 12 samples were collected by the sterile swab sticks.

First sampling was done from laboratory slab, floor, test tubes and serology discarding jars after routine work has completed.

Second sampling was done on the next day after staff has cleaned the floor, laboratory slab, test tubes and discarding jars. The staff was not informed about this procedure, so that we could see that effectiveness of the cleaning.

For the floor and slab cleaning disinfectant, which was used is phenyl. Test tubes were washed by the spirit and discarding jar, which was filled by hypochlorite solution.

Third sampling was done after all the disinfectants are calibrated with all standard operating procedure was followed for cleaning and mopping.

\begin{tabular}{|c|c|c|c|c|}
\hline $\begin{array}{c}\text { Sampling } \\
\text { Point }\end{array}$ & $\begin{array}{c}\text { Dis- } \\
\text { infectant } \\
\text { Used }\end{array}$ & \begin{tabular}{c|} 
First \\
Sampling
\end{tabular} & $\begin{array}{c}\text { Second } \\
\text { Sampling } \\
\text { (Without } \\
\text { Monitoring) }\end{array}$ & \begin{tabular}{|c|} 
Third \\
Sampling \\
(With \\
Monitoring)
\end{tabular} \\
\hline $\begin{array}{l}\text { Floor } \\
\text { Surface }\end{array}$ & Phenyl & \begin{tabular}{|c|} 
After \\
routine \\
work \\
completed
\end{tabular} & $\begin{array}{c}\text { When cleaning } \\
\text { was completed } \\
\text { by auxiliary } \\
\text { staff }\end{array}$ & $\begin{array}{l}\text { Cleaning with } \\
\text { prescribed } \\
\text { manner with } \\
\text { calibrated } \\
\text { disinfectant }\end{array}$ \\
\hline $\begin{array}{l}\text { Working } \\
\text { Slab } \\
\text { Surface }\end{array}$ & Phenyl & $\begin{array}{c}\text { After } \\
\text { routine } \\
\text { work } \\
\text { completed }\end{array}$ & $\begin{array}{c}\text { When cleaning } \\
\text { was completed } \\
\text { by auxiliary } \\
\text { staff }\end{array}$ & $\begin{array}{l}\text { Cleaning with } \\
\text { prescribed } \\
\text { manner with } \\
\text { calibrated } \\
\text { disinfectant }\end{array}$ \\
\hline Glass & $\begin{array}{c}70 \% \\
\text { alcohol }\end{array}$ & $\begin{array}{c}\text { Used } \\
\text { Glassware }\end{array}$ & $\begin{array}{c}\text { After washing } \\
\text { of glassware }\end{array}$ & \begin{tabular}{|c|} 
After \\
washing with \\
prescribed \\
spirit \\
solution \\
\end{tabular} \\
\hline $\begin{array}{c}\text { Discarding } \\
\text { Jars }\end{array}$ & $\begin{array}{c}\text { Hypo } \\
\text { chlorite }\end{array}$ & $\begin{array}{c}\text { Without } \\
\text { disinfectant }\end{array}$ & $\begin{array}{l}\text { Filled with } \\
\text { hypochlorite } \\
\text { solution }\end{array}$ & $\begin{array}{c}\text { Filled with } \\
1 \% \text { hypo- } \\
\text { chlorite } \\
\text { solution } \\
\end{array}$ \\
\hline
\end{tabular}

From each swab, lawn culture was done on the nutrient agar plate and MacConkey plates and these swab stick immediately dipped in thioglycolate liquid medium. These liquid medium and culture plates are incubated for 24 hours at $37^{\circ} \mathrm{C}$ incubator.

After 24-hour colonies were grown in culture plates and turbidity were measured in liquid medium. If there was no growth occurrence in TG broth and in culture plates, additional 24-hour incubation was done. Then subculture was done in nutrient agar and MacConkey agar.

Colony forming units were counted by the colony counter.

\section{RESULTS}

Before disinfection isolated microorganisms were Escherichia coli, Pseudomonas aeruginosa, Candida spp., Enterobacter spp., environmental filamentous fungi, Staphylococcus, environmental micrococcus and environmental bacillus. One of the main limitations of the study is the availability of suitable disinfectants, as there are different factors that affect the action of these disinfectants.

Areas hardest to clean and reasonably accessible were evaluated by direct sampling method, leading to establishing a level of contamination or residue per given surface area. The suitability of the material to be used for sampling and of the sampling medium was determined. The ability to recover a sample accurately may be affected by the choice of sampling material. For instance, it is important to assure that the sampling medium and solvent (used for extraction from the medium) were satisfactory and can be readily used. 
Time performance and product concentration usually by increasing the contact time increases the fatality rate. The contact time is one of the critical factors to ensure disinfection. Usually been experimentally established a time of 5 minutes, in which time can be determined by lethality bacterial sanitisers.

\section{Surface Action}

The choice of materials and processing was performed on the surfaces in order to retain the smallest number of bacteria after cleaning and disinfection was crucial in order to ensure the hygiene of the surfaces and thus prevent crosscontamination

Number of the colonies was counted by the help of colony counter. Comparison of number of colonies was done by logarithm.

\section{Acceptance Criteria}

Minimum $\log -3$ to $\log -5 \mathrm{CFU}$ reduction vegetative bacteria, yeast and mould spores achieved minimum log-2 CFU reduction in bacterial spores. ${ }^{2}$

After disinfecting with non-calibrated disinfectant without specified contact time, there was unsatisfactory log reduction found for various microorganisms. When all disinfectants were used in calibrated and prescribed manner with all SOPs followed, there were satisfactory results.

\section{Data Analysis}

Data will be summarised and classified in MS Excel Worksheet in the form of Master Chart. Data will be analysed and interfered with use of appropriate statistics.

\begin{tabular}{|c|c|c|c|}
\hline $\begin{array}{c}\text { Micro- } \\
\text { organisms }\end{array}$ & $\begin{array}{c}\text { Acceptance } \\
\text { Criteria } \\
\text { (Logarithmic) }\end{array}$ & $\begin{array}{c}\text { Log } \\
\text { Reduction } \\
\text { before } \\
\text { Calibrated } \\
\text { Disinfection }\end{array}$ & $\begin{array}{c}\text { Log } \\
\text { Reduction } \\
\text { after } \\
\text { Calibrated } \\
\text { Disinfection }\end{array}$ \\
\hline Escherichia coli & 3 & $<3$ & $>3$ \\
\hline $\begin{array}{c}\text { Pseudomonas } \\
\text { aeruginosa }\end{array}$ & 3 & $<3$ & $>3$ \\
\hline Micrococcus & 3 & $<3$ & $>3$ \\
\hline $\begin{array}{c}\text { Environmental } \\
\text { bacillus }\end{array}$ & 3 & $<3$ & $>3$ \\
\hline Candida spp. & 2 & $<2$ & $>2$ \\
\hline $\begin{array}{c}\text { Environmental } \\
\text { fungi }\end{array}$ & 2 & $<2$ & $>2$ \\
\hline Staphylococcus & 3 & $<3$ & $>3$ \\
\hline \multicolumn{2}{|c|}{ Table $\mathbf{2}$} \\
\hline
\end{tabular}

\section{DISCUSSION}

This study evaluated and compared the practically achieved disinfection efficacy of some routinely available disinfectants used on surfaces in this hospital. It is difficult to validate a manual cleaning procedure, i.e. an inherently variable/cleaning procedure. Therefore, operators carrying out manual cleaning procedures should be adequately trained, sensitised, monitored and periodically assessed. ${ }^{3-5}$ Therefore, we chose to test the disinfectants on multidrugresistant isolates that are circulating in our hospital environment. The type of surface to be disinfected and applications for the product must always be considered. An ideal disinfectant should have a broad antimicrobial spectrum, should be non-irritating, less toxic, non-corrosive and inexpensive.

As expected, this study showed that all disinfectants were highly effective in killing microbes on the smooth steel surface as compared with the rough surface. The decrease in efficacy of the test disinfectants on rough surface may be attributed to presence of organic matter, protection provided to the organisms and increased adherence. ${ }^{3}$

ICC members must check the disinfectant's concentration and procedure regularly. Use test strips provided by manufacturer to check for appropriate concentration of disinfectant. The detailed planning of equipment, accessories, materials and adequate instruments and other devices is needed for effective planning in surgery and other hospital areas. Cleaning and disinfection procedures in this context should follow the protocols and guidelines of material and equipment manufacturers. Cleaning agents need to be tested before their approval. Adequate resources have to be assured for professionals, equipment and the work environment.

Our findings support those of others and suggest that current validation standards (in vitro and in vivo) used for the development of commercially available disinfectants by manufacturer do not accurately reflect in-use hospital practices, which is determined by various factors. The success of a disinfectant program is directly related to the quality of training provided to the personnel charged with executing the program and the degree to which they comply with the disinfectant protocol.

\section{CONCLUSION}

Most disinfectant program failures occur either because the wrong chemistry disinfectant was selected or because the right chemistry is not applied properly as per SOP. A careful assessment of its physical area is needed with a view to improvement and the installation of adequate resources to carry out techniques in material traceability and professional and environmental safety. Protocols, procedures and written routines need to be validated in terms of applicability and to be readily available in each area, depending on its specific characteristics. Their results should be critically assessed to the benefit of patients, guaranteeing competence with accountability and high-quality practice.

Developing, validating and assuring the implementation of an overall system for cleaning and disinfection are critical. Without a system-based approach, the efforts will be thwarted by problematic situations. The control of contamination, the review of environmental monitoring data, the conducting and review of assessment data, the appropriate application and continued supervision and training all combine to ensure success.

The assessment activities of cleaning cover the identification of the microorganism, the selection of sample method, establish the approach of acceptance for residual, assessment of the method and studies of recovery.

The success obtained of assessment program for cleaning has been due to a good preparation and implementing appropriate tools of cleaning and disinfection assessment.

Training of the personnel should include basic microbiology and basic chemistry related to disinfectant preparation and application. These minute awareness and sensitisation can stop many hospital-acquired infection outbreaks. 


\section{REFERENCES}

[1] Reybrouck G. The testing of disinfectants. International Biodeterioration \& Biodegradation 1998;41:269-72.

[2] Rogers M. Disinfectant efficacy testing for critical environments. Steris life science, Greenville NC April 18, 2013.

[3] Rutala WA, Weber DJ. Surface disinfection: should we do it? J Hosp Infect 2001;48(Suppl A):S64-8.

[4] Wilcox MH, Fawley WN, Wigglesworth $N$, et al. Comparison of the effect of detergent versus hypochlorite cleaning on environmental contamination and incidence of clostridium difficile infection. J Hosp Infect 2003;54(2):109-14.
[5] White LF, Dancer SJ, Robertson C. A microbiological evaluation of hospital cleaning methods. Int J Environ Health Res 2007;17(4):285-95.

[6] Center for disease control. [home page in the Internet] Atlanta: CDC; C 2002. [cited 2002 April 12] Rutala WA, Weber JD. Draft guideline for disinfection and sterilization in healthcare facilities. Available from: http://www.cdc.gov.

[7] Schultz JK. Decontamination: recommended practices, In: Reichert M. Sterilization technology for the health care facility. $2^{\text {nd }}$ edn. Gaithersburg: Aspen, 1997:10-20.

[8] Spry C. Renewed interest in instrument cleaning. Surg Serv Manage 2000;6(4):17-20. 